\title{
Forty-two supernumerary marker chromosomes (SMCs) in 43273 prenatal samples: chromosomal distribution, clinical findings, and UPD studies
}

\author{
Oliver Bartsch ${ }^{* 1,2}$, Anne Loitzsch ${ }^{2}$, Peter Kozlowski ${ }^{3}$, Marie-Luise Mazauric ${ }^{3}$ \\ and Gabriele Hickmann ${ }^{3}$
}

\author{
${ }^{1}$ Institute for Human Genetics, Mainz University School of Medicine, Mainz, Germany; ${ }^{2}$ Institute of Clinical Genetics, \\ Dresden University of Technology, Dresden, Germany; ${ }^{3}$ Center for Prenatal Diagnosis and Genetics, \\ Düsseldorf, Germany
}

Fluorescence in situ hybridization (FISH) analyses were performed on supernumerary marker chromosomes (SMCs) detected in 43273 prenatal diagnoses over a period of 11 years, 1993-2003. A total of 42 pregnancies with SMC were identified, indicating a prevalence of one in 1032. A total of 15 SMCs were endowed with detectable euchromatin (prevalence, 1/2884), including six SMCs containing the cat eye critical region (CECR) on chromosome 22q11.21 (1/7212). De novo SMCs were found in 29 pregnancies $(1 / 1492)$, including 14 euchromatic SMCs (48.2\%). Follow-up studies were available for 24 cases. Nine pregnancies $(37.5 \%)$ were terminated; two children $(8.3 \%)$ were born with Pallister-Killian syndrome and cat eye syndrome (CES), respectively; 13 children (54.1\%) showed apparently normal development. Familial SMCs were identified in 13 pregnancies (1/3328) from 11 unrelated women. They were all acrocentric. In all, 10 were heterochromatic and one was an extra $\operatorname{der}(22) t(11 ; 22)$ chromosome. A total of 12 cases were available for follow-up. One pregnancy was terminated due to anhydramnios, spina bifida, and cystic-dysplastic kidneys; one child suffered from a der(22) syndrome; 10 children (83.3\%) appeared unaffected. Studies for uniparental disomy were performed on seven pregnancies and revealed a case of maternal heterodisomy for chromosome 22. So far this is the largest FISH study of prenatally ascertained SMCs and the first study with detailed data on the prevalence. Findings illustrate the spectrum and clinical outcomes of prenatally diagnosed SMCs, and indicate a higher frequency of SMCs than generally assumed. European Journal of Human Genetics (2005) 13, 1192-1204. doi:10.1038/sj.ejhg.5201473;

published online 3 August 2005

Keywords: prenatal diagnosis; supernumerary marker chromosomes; frequency; clinical outcome; uniparental disomy

\section{Introduction}

Supernumerary marker chromosomes (SMCs) are disturbing findings at prenatal diagnosis ${ }^{1}$ that have been reported to occur at frequencies between $1.5 / 1000^{2}$ and $0.4 / 1000 .^{3}$

*Correspondence: Priv-Doz Dr O Bartsch, Institut für Humangenetik, Universitätsklinikum, Langenbeckstr. 1, D-55101 Mainz, Germany.

Tel: + 49613117 5791; Fax: + 496131175690 ;

E-mail: bartsch@humgen.klinik.uni-mainz.de

Received 17 January 2005; revised 22 June 2005; accepted 28 June 2005; published online 3 August 2005
Fluorescence in situ hybridization (FISH) has greatly improved the prenatal analysis of SMCs. ${ }^{4-8}$ Although most cases have been characterized by standard FISH, special techniques such as chromosomal microdissection, ${ }^{9}$ subcentromere-specific multifluor FISH (subcenM-FISH), and multicolor banding (MCB) have been applied to exceptional cases. ${ }^{7}$

Occasionally, SMCs lead to spontaneous abortions. Specific SMCs have been associated with Pallister-Killian syndrome (Online Mendelian Inheritance in Man (OMIM) 
601803), inverted duplication $15 \mathrm{q} 12-\mathrm{q} 13$ syndrome, isochromosome 18p syndrome, and cat eye syndrome (CES) (OMIM 115470). However, the majority of SMCs do not grossly interfere with fetal development, because they contain little or no euchromatin. In many cases, the clinical outcome is hard to predict because the euchromatic content of the SMC is unclear, because of the different degrees of mosaicism, and the possibility of uniparental disomy (UPD). Hence, genetic counseling after identification of an SMC is complicated. Familial SMCs confer low risks. The empirical risk for congenital anomalies is approximately 13\% for randomly associated de novo SMCs, ${ }^{3-6} 7 \%$ for SMCs derived from acrocentric chromosomes (excluding the $15 \mathrm{~s}$ ), and $28 \%$ for SMCs derived from nonacrocentric autosomes. ${ }^{10}$ As a result of the high risks and many uncertainties regarding the clinical outcome, many pregnancies with de novo SMC are terminated. However, effective FISH studies can reduce uncertainties, giving affected couples a better reproductive choice.

Here, we present an 11-year survey of prenatally ascertained SMCs, which were all studied by FISH. During the study period (1993-2003), 42 pregnancies with an SMC were identified in 43273 consecutive prenatal diagnoses.

\section{Materials and methods Study and subjects}

Cases were ascertained by a survey of prenatal karyotypes from 43273 pregnancies that had been analyzed after amniocentesis (AC), chorionic villus sampling (CVS), or fetal blood sampling (FBS) at the Center for Prenatal Medicine and Genetics, Düsseldorf, Germany, from January 1, 1993 until December 31, 2003. SMCs were detected in 42 pregnancies of 40 unrelated women (five CVS, 37 amniocenteses; Tables 1 and 2). Prenatal diagnosis was performed because of advanced maternal age (AMA, $\geqslant 35$ years) in 29 women, a maternal age of 34 years combined with anxiety (cases 1, 3, 13, and 31), abnormal fetal ultrasound (cases 5, 7, 10, and 28), a previous pregnancy with familial SMC (cases 7 and 17), a maternal age of 15 years (case 27), extreme anxiety (case 35), and an uncharacterized SMC in the partner (case 39). Cases included three twin pregnancies, each with an SMC present in only one twin (cases 1, 12, and 26). The chromosomal origin, whether de novo or familial, was determined by parental karyotyping. When no SMC was found in both parents, it was considered de novo. Follow-up studies were performed using medical reports and telephone interviews of the women and/or physicians. Seven cases from this study were previously reported (see Results section).

\section{Cytogenetic and FISH analyses}

Standard karyotyping was performed using $\mathrm{G}$ banding at a resolution of 400 or more bands. SMCs were further characterized by using 4,6-diamidino-2-phenyl-indole (DAPI) staining and, in some cases, AgNOR staining. FISH was performed on metaphase spreads from AC, CVS, or FBS. SMCs were classified according to Plattner et $\mathrm{al}^{12}$ with some modifications (Table 3). Bisatellited SMCs (classes I and II) were studied with DNA probes detecting for $\beta$-satellite DNA in the acrocentric short arms, the $\alpha$-satellite subsets on chromosomes 13 and 21 (D13Z1/D21Z1), 14 and 22 (D14Z1/D22Z1), 15 (D15Z1, D15Z4), and 22 (D22Z2). SMCs(15) and SMCs(22) were further investigated with probes for the Prader-Willi/Angelman region (PW/ ACR) and CECR. Minute ring-like SMCs (classes III and IV) were assigned to alphoid suprafamilies using reduced stringency conditions and alphoid DNA probes for chromosomes 10 (D10Z1, a member of suprafamily 1 on chromosomes $1,3,5,6,7,10,12,16$, and 19), 8 (D8Z2; family 2 on $2,4,8,9,13,14,15,18,20,21$, and 22), $\mathrm{X}$ (DXZ1; family 3 on X, 11, 17, and 1), and Y (DYZ3; family 4 on $Y, 4$, and 15$).{ }^{13}$ in a second step, minute SMCs were studied under standard FISH conditions with the appropriate chromosome-specific alphoid DNA probes, locusspecific probes, and/or chromosome paints (Tables 1 and 2 ). An analphoid minute (case 13) required chromosomal microdissection. ${ }^{9}$ Other SMCs (class V) showed informative banding patterns that were confirmed by hybridization of the appropriate DNA probes. DNA probes (Tables 1 and 2) were purchased from Appligene/Oncor (Illkirch, France) and Vysis (Downers Grove, IL, USA). Plasmids pUC1.77 and pHUR195 (D1Z satellite III DNA at chromosome 1q12 and D16Z4 at 16q11.2, kindly provided by Dr Joop Wiegant, Leiden University, The Netherlands) were labeled using nick translation. DNAs of cosmids, BACs, and YACs (Tables 1 and 2) were amplified and labeled as described in previous studies. ${ }^{14,15}$ SMCs(22) were analyzed using cosmid $\cos 121^{16}$ and, following the report of McTaggart et al, ${ }^{17}$ additional BAC clones (Tables 1 and 2). ${ }^{11}$ Slides were counterstained with DAPI and analyzed using Axioskop ${ }^{\mathrm{TM}}$ epifluorescence microscopes (Carl Zeiss, Göttingen, Germany) and the ISIS $^{\mathrm{TM}}$ imaging system (MetaSystems, Altlussheim, Germany). At least six informative metaphases were scored for each probe.

\footnotetext{
Molecular studies

Following reports on SMCs and UPD, ${ }^{18,19}$ UPD analysis of the chromosomes homologous to the SMC was performed in a subset of cases, if the result could aid the woman in her decision on how to proceed with the pregnancy. Fetal and parental DNAs were available for cases 14, 17A, 17B, 34, 36, 38 , and 39. Between four and nine different polymorphic DNA markers (see Results section), spaced over the entire chromosome, were analyzed using the ABI 310 Genetic
} 


\begin{tabular}{|c|c|c|c|c|c|c|c|c|}
\hline Case no. & $\begin{array}{l}\text { Reason for prenatal } \\
\text { diagnosis }\end{array}$ & $\begin{array}{l}\text { Chromosomal } \\
\text { origin }\end{array}$ & $\begin{array}{l}\text { Percentage of cells } \\
\text { with } S M C^{(}(\%)\end{array}$ & $\begin{array}{l}\text { Euchromatin } \\
\text { detected }\end{array}$ & Class $^{\mathrm{b}}$ & $\begin{array}{l}\text { Result of UPD } \\
\text { studies }\end{array}$ & Karyotype & $\begin{array}{l}\text { Clinical observations } \\
\text { and follow-up }\end{array}$ \\
\hline 13 & Age 34 and anxiety & 1 & 50 & Yes & IV & - & $\begin{array}{l}47, \mathrm{XY},+\mathrm{mar} / 46, \mathrm{XY}, \mathrm{rev} \text { ish and ish } \\
\mathrm{r}(1)(\mathrm{q} 43 \mathrm{q} 44)(\mathrm{wcp} 1+, \mathrm{D} 1 \mathrm{Z}-\mathrm{D}-\mathrm{D} 1 \mathrm{Z7} / \mathrm{D} 5 \mathrm{Z} 2 / \mathrm{D} 19 \mathrm{Z3}-, \mathrm{D} 1 \mathrm{S5} 55 /\end{array}$ & $\begin{array}{l}\text { Liveborn, normal at } 6 \\
\text { months }\end{array}$ \\
\hline 34 & Age 40 & 1 & 25 & Yes & IV & Normal & $\begin{array}{l}\text { 47,XX,+mar[7]/46,XX[21].ish r(1)(p11.1q21.1)(RP5-940/24/ } \\
\text { AL159950-,D1Z5,+D1Z7/D5Z22/D19Z3+,pUC1.77/ } \\
\text { D1Z+,RP11-35B4/AL359093+) }\end{array}$ & Not available \\
\hline 35 & Anxiety & 4 & 60 & No & III & - & $47, X X,+\operatorname{mar}[20] / 46, X X[13] . i s h r(4)(p 11 q 11)(D 4 Z 1+)$ & TOP, no anomalies \\
\hline 38 & Age 39 & 6 & 83 & No & III & Normal & $\begin{array}{l}\text { 47,XX, } \mathrm{Xmar}[26] / 46, \mathrm{XX}[5] . \text { ish } \\
\mathrm{r}(6)(\mathrm{p} 11 \mathrm{q} 11)(\mathrm{pcp} 6 \mathrm{p}-, \mathrm{RP} 11-362 \mathrm{~K} 18 / \\
\text { AL365328.18-,D6Z1+, pcp6q-, RP11-387L5/AL512368.9-) }\end{array}$ & $\begin{array}{l}\text { Delivery using vacuum } \\
\text { extractor at week } 39 \text {, } \\
\text { birth weight } 2830 \mathrm{~g} \text {, } \\
\text { no congenital } \\
\text { anomalies, normal } \\
\text { development at } 7 \\
\text { months }\end{array}$ \\
\hline 3 & Age 34 and anxiety & 8 & 84 at $\mathrm{AC} 100$ at FBS & 5 No & IIII & - & $\begin{array}{l}48, X X,+2 \operatorname{mar}[4] / 47, X X,+\operatorname{mar}[17] / 46, X X[4] . i s h \\
\end{array}$ & $\begin{array}{l}\text { Liveborn, normal at } 6 \\
\text { vears }\end{array}$ \\
\hline 32 & Age 42 & 8 & 20 at CVS 60 at AC & Yes & IV & - & 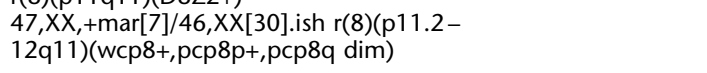 & TOP, no postmortem \\
\hline & Age 44 & 11 & 72 & No & III & - & 47,XY,+mar[32]/46,XY[12].ish r(11)(p11q11)(wcp11-,baclB1/ & Liveborn, normal at 3 \\
\hline 5 & $\begin{array}{l}\text { Abnormal US, } \\
\text { polyhydramnion, } \\
\text { esophageal atresia }\end{array}$ & 12 & 50 & Yes & $\mathrm{v}$ & - & $47, X Y,+\operatorname{mar}[10] / 46, X Y[10]$. ish $\mathrm{i}(12)(\mathrm{p} 10)($ wcp $12+)$ & $\begin{array}{l}\text { Pallister-Killian } \\
\text { syndrome, premature } \\
\text { delivery at } 33 \text { weeks, } \\
\text { died } 1 \text { day old }\end{array}$ \\
\hline 12 & Age 40 & $13 / 21$ & 66 & No & I & - & $47, \mathrm{XX},+$ mar/46,XX.ish i $(130 \mathrm{or} 1)(\mathrm{p} 10)(\mathrm{D} 13 \mathrm{Z1} / \mathrm{D} 21 \mathrm{Z1}+)^{\mathrm{cd} d}$ & Liveborn, normal at 4.5 \\
\hline 16 & Age 35 & $13 / 21$ & 100 & No & । & - & $\begin{array}{l}\text { 49,XY,+3mar[8]/47,XY,+mar[10].ish i(13or21)(p10)(D13Z1/ } \\
\text { D21Z1+d }\end{array}$ & $\begin{array}{l}\text { Liveborn, normal at } 3 \\
\text { vears }\end{array}$ \\
\hline 21 & Age 41 & $13 / 21$ & 100 & No & 1 & - & $\begin{array}{l}\text { 47, XY, +mar.ish i(13or21)(p10)(wcp13-,wcp21-,D13Z1/ } \\
\text { D21Z1 + })^{d}\end{array}$ & $\begin{array}{l}\text { Liveborn, normal at } 3 \\
\text { years }\end{array}$ \\
\hline 1 & Age 34 and anxiety & 15 & 100 & Yes & ॥ & - & $47, \mathrm{XX},+$ mar.ish $\operatorname{dic}(15)(\mathrm{q} 13)(\mathrm{D} 15 \mathrm{Z1++}, \mathrm{D} 15 \mathrm{S11++})$ & TOP \\
\hline 4 & Age 37 & 15 & 50 & No & 1 & - & $47, X Y,+\operatorname{mar}[10] / 46, X Y[10] . i s h$ & Liveborn, normal at 6 \\
\hline 10 & $\begin{array}{l}\text { Abnormal US, } \\
\text { nuchal edema, } \\
\text { heart defect, } \\
\text { hydronephrosis }\end{array}$ & 15 & 50 at $\mathrm{AC} 66$ at $\mathrm{FBS}$ & Yes & $\mathrm{v}$ & - & 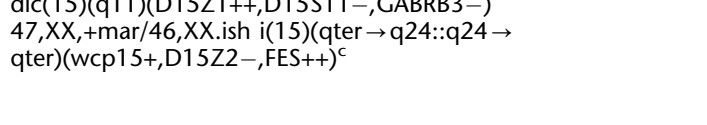 & $\begin{array}{l}\text { yoars } \\
\text { TOP, mild growth } \\
\text { retardation and renal } \\
\text { abnormalities at } \\
\text { postmortem }\end{array}$ \\
\hline 14 & Age 36 & 15 & 100 & No & $\mathrm{I}$ & Normal & $\begin{array}{l}\text { 47,XY,+mar.ish } \\
\text { dic(15)(a1)(D1571++D1572++D15S11-SNRPN-D15S10-) }\end{array}$ & Liveborn, normal at 3 \\
\hline 11 & Age 35 & 16 & 63 & No & III & - & $\begin{array}{l}47, \mathrm{XY}, \mathrm{mar}[60) / 46, \mathrm{XY}[34] \mathrm{ish} \\
\mathrm{r}(16)(\mathrm{p} 11 \mathrm{q} 11.2)(\mathrm{wcp} 16-, \mathrm{D} 16 \mathrm{Z} 2+, \mathrm{D} 16 \mathrm{ZZ}+)\end{array}$ & $\begin{array}{l}\text { yoars } \\
\text { TOP malformations } \\
\text { on inspection, no }\end{array}$ \\
\hline 31 & Age 34 and anxiety & 16 & 70 & No & III & - & $\begin{array}{l}\text { 47,XX,+mar[21]/46,XX[9].ish r(16)(p11 q11.2)(D16Z2+,D16Z4 } \\
\text { dimwcol } 6 \text { dim) }\end{array}$ & TOP, no post-mortem \\
\hline 30 & Age 37 & 17 & 67 & No & III & - & $47, \mathrm{XX},+\operatorname{mar}[36] / 46, \mathrm{XX}[17] . \operatorname{sish} \mathrm{r}(17)(\mathrm{p} 11 \mathrm{q} 11)(\mathrm{D} 17 \mathrm{Z1}+, \mathrm{wcp} 17-)$ & Liveborn, normal at 4 \\
\hline 19 & Age 39 & 18 & 100 & Yes & $\mathrm{v}$ & - & $\begin{array}{l}\text { 47,XY,+mar.ish i(18)(p10)(wcp18+,yac854G8/ } \\
\text { D18s476++,D18Z1+) }\end{array}$ & TOP, no postmortem \\
\hline $\begin{array}{l}23 \\
15\end{array}$ & $\begin{array}{l}\text { Age } 38 \\
\text { Age } 41\end{array}$ & $\begin{array}{l}18 \\
19\end{array}$ & $\begin{array}{l}100 \\
63 \text { at } A C 30 \text { at FBS }\end{array}$ & $\begin{array}{l}\text { Yes } \\
\text { Yes }\end{array}$ & $\begin{array}{l}\mathrm{V} \\
\text { IV }\end{array}$ & 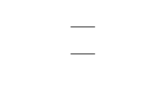 & 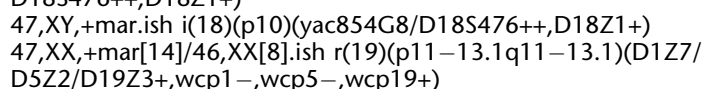 & $\begin{array}{l}\text { TOP, no postmortem } \\
\text { Liveborn, normal at } 3 \\
\text { years }\end{array}$ \\
\hline 25 & Age 35 & 21 & 78 & No & III & - & $\begin{array}{l}47, \mathrm{XY},+\operatorname{mar}[26] / 46, \mathrm{XY}[\mathrm{f}] . \text { ish r(21)(p11q11)(D13Z1/ } \\
\text { D21Z1+,wcp13-,wCp21+) }\end{array}$ & Normal at 2 years \\
\hline 8 & Age 38 & 22 & $\mathrm{ND}$ at $\mathrm{AC} 30$ at FBS & No & I & - & 47,XY, tmar[3]/46, XY[7].ish i(22)(p10)(D22Z2++, $\cos 121 /$ & Normal at 5 years \\
\hline 9 & Age 37 & 22 & 100 & Yes & IV & - & $47, \mathrm{XX}$, +mar.ish r(22)(p11q11.2)(D22Z2+,D14Z1/ & TOP, no postmortem \\
\hline
\end{tabular}




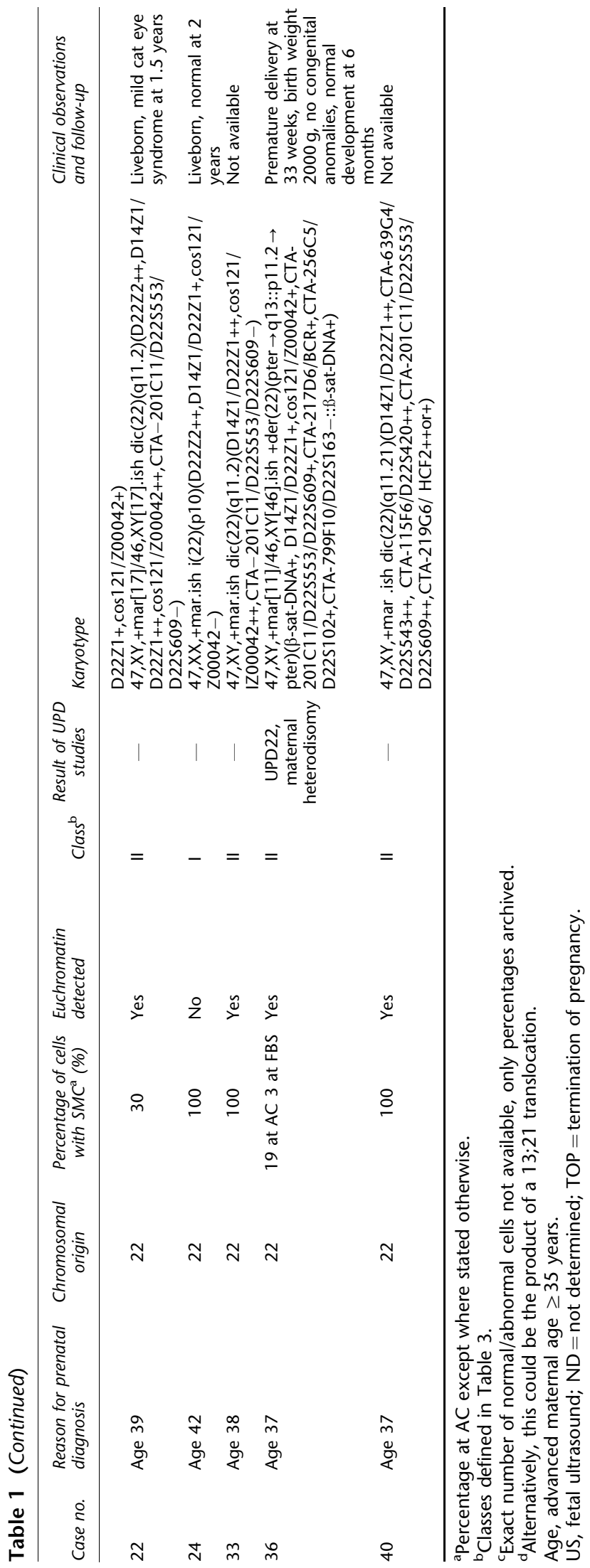

Analyzer. Paternity testing was not performed due to legal restrictions.

\section{Results \\ De novo SMCs}

Table 1 summarizes the cases with de novo SMCs and provides the FISH karyotypes. Figure 1 shows representative $\mathrm{G}$ banding results. Figure 2 shows results after FISH. In total , 29 (72.5\%) of the 40 different SMCs were de novo. Of these, nine (31\%) were present in all analyzed cells and 20 (69\%) demonstrated mosaicism. Apart from case 16, all mosaics showed another cell line with a normal karyotype. Case 16 had three copies of the SMC in most cells and one SMC in the other cells. Four pregnancies were studied for UPD, one with an abnormal result (case 36, see Chromosome 22).

Chromosome 1 Case 13: As reported previously (case 1), ${ }^{9}$ an AC was performed at $15+4$ weeks of gestation. Karyotyping showed a minute SMC in 50\% of the cells. Absence of alphoid DNA using FISH suggested a neocentric SMC. After chromosomal microdissection and reverse painting, and FISH studies using a subtelomeric probe for 1q (Oncor P5402, D1S555/D1Z9), the SMC was found to represent 1q43-q44, excluding the 1q subtelomeric region. Apart from a transient bigeminal pulse, no abnormalities were noted in neonatal age. The mother reported a normal development at the age of 6 months.

Case 34: An AC was performed at $15+3$ weeks of gestation. Karyotyping demonstrated a minute round DAPI-positive SMC (Figure 1) in 25\% of the cells and FISH indicated trisomy for the pericentromeric area of chromosome 1 and for a small segment from 1q21 (Figure 2). Fetal ultrasound at 16 weeks was normal. Molecular studies showed normal biparental inheritance at loci D1S1646, D1S550, D1S1595, and D1S180, excluding UPD1. The pregnancy was continued but not available for follow-up.

Chromosome 4 Case 35: This 25-year-old woman requested an AC at $14+5$ weeks of gestation because her partner had a brother with mental retardation of unknown origin. The ultrasound at $14+5$ weeks showed a normal male fetus. A small ring-like DAPI-positive SMC (Figure 1) was evident in $60 \%$ of the cells. FISH demonstrated a minute ring composed entirely of pericentric heterochromatin from chromosome 4 (Figure 2). The pregnancy was terminated at $19+2$ weeks of gestation. Autopsy showed no external or internal fetal anomalies.

Chromosome 6 Case 38: An AC was performed at $14+2$ weeks of gestation. A detailed fetal ultrasound was normal. $\mathrm{G}$ banding (Figure 1) and DAPI staining revealed a minute ring-like DAPI-positive SMC in $83 \%$ of the cells. The FISH signal with the alphoid probe for chromosome 6 covered 
Table 2 Thirteen pregnancies (11 different families) with familial supernumerary marker chromosomes

\begin{tabular}{|c|c|c|c|c|c|c|c|}
\hline $\begin{array}{l}\text { Case } \\
\text { no. }\end{array}$ & $\begin{array}{l}\text { Reason for } \\
\text { prenatal dignosis }\end{array}$ & $\begin{array}{l}\text { Chromosomal } \\
\text { origin }\end{array}$ & $\begin{array}{l}\text { Percentage of } \\
\text { cells with SMC } \\
\text { (\%) }\end{array}$ & Class $^{\mathrm{b}}$ & $\begin{array}{l}\text { Result of UPD } \\
\text { studies }\end{array}$ & Karyotype & $\begin{array}{l}\text { Clinical observations and } \\
\text { follow-up }\end{array}$ \\
\hline 27 & Age 15 years & $13 / 21$ & 100 & I & - & $47, \mathrm{XY},+$ mar.ish i(13or21)(p10)(D13Z1/D21Z1+)mat ${ }^{\mathrm{C}}$ & Liveborn, normal at 1 year \\
\hline 37 & Age 35 years & $13 / 21$ & 100 & $\mathrm{i}$ & - & $\begin{array}{l}\text { 47, XY, +mar.ish i(13or21)(p10)( } \beta- \\
\text { satellite-DNA++,D13Z1/D21Z1+)pat }\end{array}$ & $\begin{array}{l}\text { Emergency birth at } 28 \text { weeks } \\
\text { after premature ablation of } \\
\text { the placenta, normal at } 1 \\
\text { year }\end{array}$ \\
\hline 6 & Age 35 years & $13 / 21$ and 15 & 100 & I & - & $\begin{array}{l}\text { 47,XX,+mar.ish } \\
\text { der(13or21;15)(p10p10)(wcp13-,D13Z1/D21Z1+, } \\
\text { wcp15-,D15Z1+,D15S11-,wcp21-)mat }\end{array}$ & Liveborn, normal at 5 years \\
\hline $17 \mathrm{~A}$ & Age 36 years & 15 & 100 & 1 & Normal & $\begin{array}{l}\text { 47,XY,+mar.ish } \\
\operatorname{dic}(15)(\mathrm{q} 11)(\mathrm{D} 15 \mathrm{Z} 1++, \mathrm{D} 15 \mathrm{Z2++}, \mathrm{SNRPN}-) \mathrm{mat}\end{array}$ & Liveborn, normal at 3 years \\
\hline $17 \mathrm{~B}$ & $\begin{array}{l}\text { Age } 38 \text { years and } \\
\text { maternal SMC }\end{array}$ & 15 & 100 & I & Normal & $\begin{array}{l}\text { 47, XY,+mar.ish } \\
\operatorname{dic}(15)(q 11)(D 15 Z 1++, D 15 Z 2++, \text { SNRPN-)mat }\end{array}$ & $\begin{array}{l}\text { Liveborn, normal at } 6 \\
\text { months }\end{array}$ \\
\hline 39 & Paternal SMC & 15 & 100 at CVS & 1 & Normal & $47, X X$, +mar.ish dic(15)(q11)(D15Z1++,SNRPN-)pat & Not available \\
\hline 2 & Age 37 years & 22 & 100 & I & 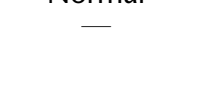 & $\begin{array}{l}48, X Y,+m a r x 2[12] / 47, X Y,+m a r[9] . i s h \\
\operatorname{dic}(22)(q 11.1)(D 14 Z 1 / D 22 Z 1++, \cos 121 / \\
Z 00042-) m a t\end{array}$ & Liveborn, normal at 6 years \\
\hline $7 \mathrm{~A}$ & Abnormal US & 22 & 100 & I & - & $\begin{array}{l}\text { 47,XY,+mar.ish i(22)(p10)(D22Z2++,D14Z1/D22Z1 } \\
\text { dim)pat }\end{array}$ & $\begin{array}{l}\text { TOP, anhydramnios, spina } \\
\text { bifida aperta, and dysplastic } \\
\text { kidneys on US, no } \\
\text { postmortem }\end{array}$ \\
\hline 7B & Paternal SMC & 22 & 100 & 1 & - & $47, X Y, t(4 ; 5)(q 28 q 33)$ de novo, $+\mathrm{i}(22)(\mathrm{p} 10)$ pat & Liveborn, normal at 4.5 years \\
\hline 18 & Age 35 years & 22 & 100 & I & - & $\begin{array}{l}\text { 47,XY,+mar.ish i(22)(p10)(D22Z2+or++,D14Z1/ } \\
\text { D22Z1-)pat }\end{array}$ & Liveborn, normal at 2.5 years \\
\hline 20 & Age 40 years & 22 & 100 & I & - & $\begin{array}{l}47, \mathrm{XY},+ \text { mar.ish i(22)(p10)(D22Z2++,D14Z1/ } \\
\mathrm{D} 22 \mathrm{Z} 1+, \cos 121 / \mathrm{Z} 00042-) \text { pat }\end{array}$ & Liveborn, normal at 2.5 years \\
\hline 26 & Age 36 years & 22 & 100 & V & - & $\begin{array}{l}\text { 47, XY,+mar.ish } \\
\text { der(22)t(11;22)(q23.3q11.2)(CTA-919E7/ } \\
\text { D22S942+,MLL+)pat }\end{array}$ & $\begin{array}{l}\text { Liveborn, multiple } \\
\text { malfomations, died } 1 \text { day } \\
\text { old }\end{array}$ \\
\hline 28 & $\begin{array}{l}\text { Nuchal } \\
\text { translucency }\end{array}$ & 22 & 100 & I & - & $\begin{array}{l}\text { 47,XX,+mar.ish i(22)(p10)(D22Z2++,D14Z1/D22Z1 } \\
\text { dim)pat }\end{array}$ & $\begin{array}{l}\text { Liveborn, aside from } \\
\text { adducted feet normal at the } \\
\text { age of } 4 \text { months }\end{array}$ \\
\hline
\end{tabular}

Percentage at AC except where stated otherwise.

${ }^{\mathrm{b}}$ Defined in Table 3.

'Alternatively, this could be the product of a 13;21 translocation.

Age, advanced maternal age $\geq 35$ years.

US, fetal ultrasound; TOP = termination of pregnancy. 
Table 3 Classification of SMCs used in the present study, prevalences of the different SMCs, and summary of chromosomal findings

\begin{tabular}{|c|c|c|c|c|}
\hline Class & Definition & Pregnancies & Prevalence & Summarized chromosomal findings \\
\hline II & $\begin{array}{l}\text { Larger bisatellited SMCs containing } \\
\text { either the PWS/AS region or the } \\
\text { CESCR }\end{array}$ & $5(11.9 \%)$ & $1 / 8654$ & $\begin{array}{l}\text { One isochromosome } 15 q 13 \\
\text { Two small (type I) CES chromosomes } \\
\text { One larger (type II) CES chromosome } \\
\text { One atypical (type III) CES chromosome }\end{array}$ \\
\hline III & $\begin{array}{l}\text { Minute ring-like SMCs showing only } \\
\text { centromere heterochromatin }\end{array}$ & $8(19 \%)$ & $1 / 5409$ & $\begin{array}{l}\text { Minutes representing chromosomes } 4 \text { cen, 6cen, } 8 \text { cen, } \\
11 \text { cen, } 16 \text { cen }(2 x), 17 \text { cen, and } 21 \text { cen }\end{array}$ \\
\hline IV & $\begin{array}{l}\text { Minute ring-like SMCs showing } \\
\text { euchromatin }\end{array}$ & $5(11.9 \%)$ & $1 / 8654$ & $\begin{array}{l}\text { Minutes conferring small proximal trisomies of } \\
1 q, 8 p, 19 p \text { and/or } q \text {, and } 22 q \\
\text { One analphoid ring chromosome } 1 q 43-q 44\end{array}$ \\
\hline
\end{tabular}

${ }^{a}$ Alternatively, these SMCs could be the product of a 13;21 translocation.

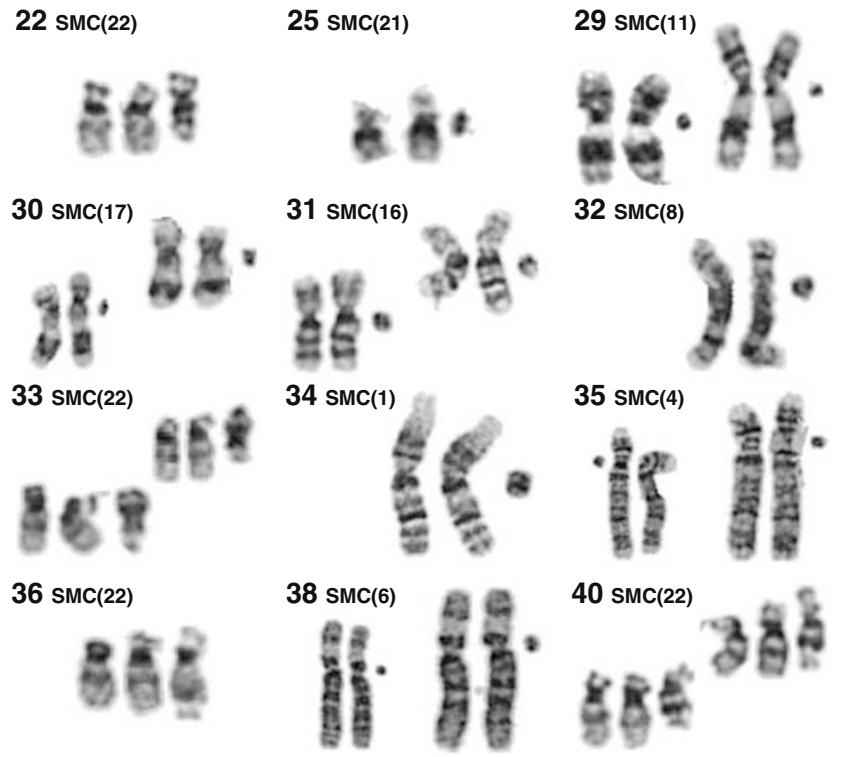

Figure 1 Partial G banded karyotypes showing SMCs and chromosomes of origin from the more recent de novo cases. Case numbers are indicated in the upper left corner. All SMCs other than the left SMC(4) (case 35) are depicted to the right of the original chromosomes.

the entire SMC (Figure 2), suggesting breakpoints within the alphoid DNA. UPD6 was excluded using nine different polymorphic markers. Seven markers (D6S477, D6S1050, D6S1031, D6S1056, D6S474, D6S1003, and D6S503) were informative and demonstrated normal biparental inheritance, excluding UPD6. The child was born at term using a vacuum extractor. Birth weight was $2830 \mathrm{~g}$, length $49 \mathrm{~cm}$, and $\mathrm{OFC} 32 \mathrm{~cm}$. No congenital anomalies were noted. The mother reported normal development at age 7 months.

Chromosome 8 Case 3: An AC was performed at $15+6$ weeks of gestation. $\mathrm{G}$ banding showed two minute circular SMCs in $16 \%$ of the cells, one SMC in $68 \%$ of the cells, and normal chromosomes in the other cells. FISH indicated an SMC(8). The hybridization signal with the alphoid probe for 8 fully covered the SMC, suggesting the absence of euchromatin. At age 6 years, the girl was phenotypically normal.

Case 32: A CVS was performed at $11+6$ weeks of gestation. Karyotyping showed a ring-like $18 \mathrm{p}$-sized SMC (Figure 1) in 14\% of the cells. Following an AC at 14 weeks of gestation, the SMC was recovered in $19 \%$ of the metaphases and characterized using multifluor FISH (24-color painting) and partial chromosome paints for $8 p$ (pcp8p) and 8q (pcp8q). Findings indicated an SMC(8) containing a minute euchromatic segment from $8 p$ and possibly also from 8q. A detailed fetal ultrasound was normal. The pregnancy was terminated.

Chromosome 11 Case 29: An AC was performed at $14+5$ weeks of gestation. G banding showed a minute SMC (Figure 1) in $72 \%$ of the cells. The FISH signal using an alphoid probe for chromosome 11 covered the entire SMC 

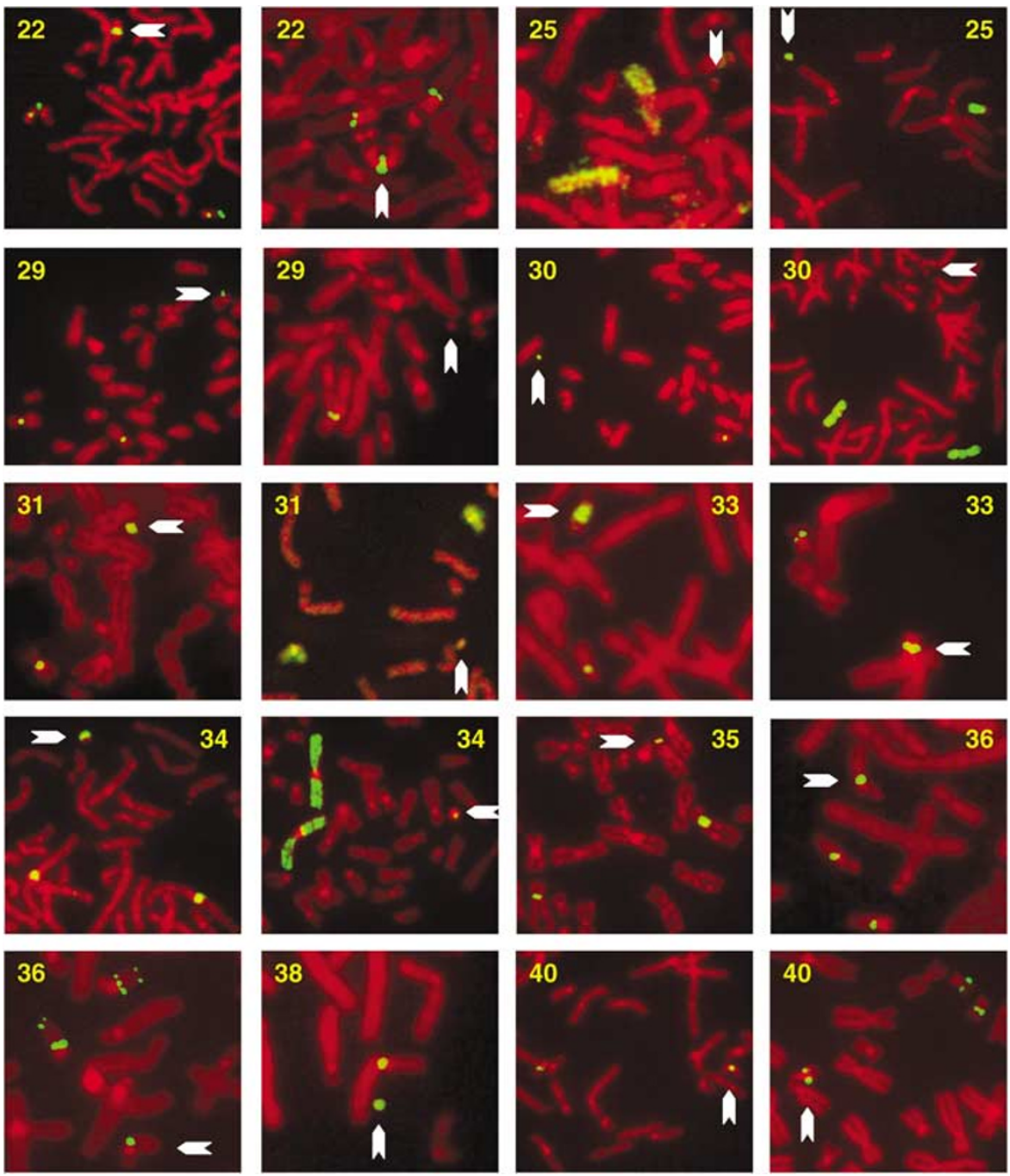

Figure 2 Partial metaphases after FISH from the more recent de novo cases. Case numbers are indicated on each image. SMCs are marked by arrows. The following DNA probes were used: case 22 (left) BAC CTA-639G4 (chromosome 22q11.1) showing two extra copies by dosage estimate on the SMC, and BAC CTA-384D8 (22q13.33), absent on SMC, (right) BAC CTA-678G6 (22q11.21), two extra copies on SMC by dosage estimate; case 25 (left) wcp13, no signal on SMC, (right) wCp21 painting the SMC; case 29 (left) alphoid probe for chromosome 11 covering the entire SMC, (right) BAC clone IB1, absent on SMC; case 30 (left) alphoid probe for chromosome 17 covering the entire minute SMC, (right) wcp17 showing no detectable euchromatin; case 31 (left) alphoid probe for chromosome 16 covering almost the entire SMC, (right) wcp16 producing a weak signal above the background noise level; case 33 (left) alphoid probe for chromosomes 14 and 22 showing two extra copies on this CES chromosome, (right) cos 121 showing two extra copies by dosage estimate; case 34 (left) D1Z satellite III DNA probe pUC1.77 identifying the SMC as a highly reduced chromosome 1, (right) wcp1 painting a small segment of the SMC; case 35 (left) alphoid probe for chromosome 4 covering the entire minute SMC; case 36 (first image) BAC CTA-678G6 one extra copy on this unusual (type III) CES chromosome, by dosage estimate from several metaphases, (second image) BAC CTA-201C11, one extra copy by dosage estimate, and BAC CTA-799F10, absent on this SMC; case 38, alphoid probe for chromosome 6 covering the entire minute SMC; case 40 (left) BAC CTA-201C11, two extra copies on this large (type II) CES chromosome by dosage estimate from several metaphases, and (right) BAC CTA-219G6, either one or two extra copies on this CES chromosome, dosage estimate not feasible.

(Figure 2). A whole chromosome paint for 11, which paints the euchromatin but not the heterochromatin, and BAC clone IB1 (a gift from Dr Gerard Waeber, University of Lausanne, Switzerland) (Figure 2), which detects the MAPK8IP1 gene at $11 \mathrm{p} 11.2$, respectively, produced no detectable signals on the SMC. Findings suggested that the SMC contained only centromere heterochromatin. The boy had no apparent anomalies at age 3 months.
Chromosome 12 Case 5: A woman had an ultrasound at $28+3$ weeks gestation showing polyhydramnion and esophageal atresia. Concomitant karyotyping by means of AC showed a nonsatellited, F-group sized metacentric SMC in $50 \%$ of the cells. An isochromosome 12p (PallisterKillian syndrome) was suspected and confirmed using FISH. The boy was born at 33 weeks of gestation and died at day one of life. 
Chromosome 13 or 21 Case 12: In this twin pregnancy, an AC was performed at $15+1$ weeks of gestation. One twin had a normal karyotype and the cotwin had a small bisatellited SMC in $66 \%$ of her cells. FISH identified a $13 p$ or $21 \mathrm{p}$ isochromosome or translocation. The twin with the SMC was phenotypically unaffected at 4.5 years. Her sister with the normal karyotype died at age of 1 year of sudden infant death.

Case 16: An AC was performed at 17 weeks of gestation. Karyotyping demonstrated three identical small, bisatellited, DAPI-negative SMCs in $45 \%$ of the cells and one SMC in $55 \%$. FISH indicated that the SMCs consisted of $13 p$ or 21p material. The boy had no apparent anomalies at the age of 3 years.

Case 21: Following an AC performed at 16 weeks of gestation, a small bisatellited SMC was evident in all cells. FISH demonstrated a $13 \mathrm{p}$ or $21 \mathrm{p}$ isochromosome or translocation. The boy had no anomalies at age 3 years.

Chromosome 15 Case 1: In this female twin pregnancy, an AC was performed at $15+4$ weeks of gestation. One twin had a large bisatellited DAPI-positive SMC and the cotwin had a normal karyotype. Using FISH, the SMC was identified as a dicentric SMC(15) with two copies of the PW/ACR. A selective termination was performed. The cotwin was normal at birth.

Case 4: An AC was performed at 15 weeks of gestation. A small bisatellited DAPI-positive SMC was found in 50\% of the cells. FISH showed a dicentric SMC(15) lacking the PW/ACR. The boy showed no anomalies at age 6 years.

Case 10: This was reported previously (case 2). ${ }^{9}$ After an ultrasound showing nuchal edema, a heart defect, and hydronephrosis, concomitant AC and FBS were performed at $22+5$ weeks of gestation. A nonsatellited, F-group sized submetacentric SMC was found in $50 \%$ and $66 \%$ of cells, respectively. FISH showed no alphoid DNA on the SMC. The banding pattern tentatively suggested an origin from the distal chromosome $15 \mathrm{q}$, which was confirmed by FISH. The pregnancy was terminated at 24 weeks. Post-mortem studies showed mild growth retardation (weight $690 \mathrm{~g}$, signs of maturity 21 weeks), bilateral hydronephrosis, polycystic left kidney (Potter IV), and dysplastic right kidney.

Case 14: An AC was performed at $14+2$ weeks of gestation. Karyotyping revealed a bisatellited DAPI-positive SMC in all cells and FISH indicated a dicentric chromosome 15 without the PW/ACR. Molecular studies indicated biparental inheritance at loci D15-ACTC, D15S659, and D15S175, excluding UPD15. The boy had no anomalies at age 3 years.

Chromosome 16 Case 11: An AC was performed at $15+6$ weeks of gestation. After $\mathrm{G}$ banding, a ring-like, 18p sized SMC was seen in $63 \%$ of the cells. The combined FISH signals with an alphoid probe for 16 (D16Z2) and a satellite
II probe (pHUR195, D16Z4) covered the entire SMC, which may have arisen from a ring chromosome 16 by subsequent deletion(s). A whole chromosome paint 16 (wcp16), which excludes the pericentric heterochromatin, showed no signal on the SMC, suggesting the absence of euchromatin DNA. After genetic counseling, ${ }^{20}$ the pregnancy was terminated at 19 weeks. Placenta weight was normal. The fetus weighed $210 \mathrm{~g}$ and showed no external malformations. Further post-mortem studies were declined.

Case 31: An AC was carried out at $16+0$ weeks of gestation and showed a circular 18p sized SMC (Figure 1) in $70 \%$ of the cells. FISH using an alphoid probe (locus D10Z1) at low stringency indicated the presence of alphoid suprafamily 1 DNA. Using an alphoid probe for chromosome 16 (locus D16Z2), a signal was present on the SMC (Figure 2). A satellite II probe (pHUR195, D16Z4) yielded a weak signal on the SMC. Similarly, the wcp16 produced very minor signals barely above the background noise level (Figure 2). Hence, the SMC contained little if any euchromatin. The detailed fetal ultrasound was apparently normal. The pregnancy was terminated. Autopsy data were not available.

Chromosome 17 Case 30: A minute ring-like SMC (Figure 1) was detected in $67 \%$ of the cells after an AC performed at $14+5$ weeks of gestation. FISH with a chromosome $17 \alpha$-satellite probe and a wcp17 revealed an SMC(17) with very little or no euchromatin (Figure 2 ). The girl had no apparent anomalies at the age of 4 months.

Chromosome 18 Case 19: A nonmosaic small metacentric SMC was evident after CVS performed at $10+6$ weeks gestation. An isochromosome 18p was suspected after karyotyping and was confirmed using FISH. The pregnancy was terminated at 12 weeks of gestation.

Case 23: This woman had an AC at $14+3$ weeks gestation. Karyotyping showed a small metacentric SMC present in all cells. An isochromosome 18p was suspected and confirmed using FISH. Detailed fetal ultrasound showed a dolichocephaly but no other anomalies. The pregnancy was terminated.

Chromosome 19 Case 15: An AC was performed at $16+4$ weeks of gestation and showed a minute ring-like SMC in $63 \%$ of the cells. Using FISH at low stringency, DNA of the alphoid suprachromosomal family 1 was present at the SMC. An alphoid probe for chromosomes 1, 5, and 19 (D1Z7/D5Z2/D19Z3) and wcp19 yielded FISH signals covering most of the SMC, whereas wcp1 and wcp5 did not hybridize with the SMC. An SMC(19) containing some euchromatin was diagnosed. The girl had no anomalies at age 3 years.

Chromosome 21 Case 25: A minute SMC was evident in $78 \%$ of the cells of an AC taken at $15+2$ weeks gestation. 
FISH indicated a minute ring-like SMC(21). Detailed fetal ultrasounds at $15+2$ and $20+2$ weeks of gestation were normal. The pregnancy was continued. The boy had no anomalies at age 2 years.

Chromosome 22 Case 8: An AC was undertaken at $18+1$ weeks of gestation. A small submetacentric bisatellited SMC was detected in a subset of cells. For confirmation and FISH, FBS was performed and the SMC was recovered in $30 \%$ of the cells. Using FISH, a dicentric chromosome $22 \mathrm{q} 11$ without the CECR was identified. The boy had no anomalies at the age of 5 years.

Case 9: A minute ring-like SMC was evident in all cells of an amniotic fluid sample taken at $14+5$ weeks gestation. Using FISH a small ring chromosome 22 including the CECR was detected. The pregnancy was terminated. Further information was declined.

Case 22: This was reported previously (patient 2). ${ }^{11} \mathrm{~A}$ small (type I) CES chromosome ${ }^{17}$ was detected in $50 \%$ of the cells in an AC. The boy reportedly had mild CES at the age of 1.5 years. Detailed medical records were not available.

Case 24: A CVS at $10+6$ weeks of gestation was performed, and disclosed a small bisatellited SMC in all cells. FISH indicated an isochromosome $22 \mathrm{p}$ without the CECR. The girl had no anomalies at age 2 years.

Case 33: This was previously reported (patient 3). ${ }^{11}$ Following a strong vaginal bleeding in the first trimester, an AC was performed at $14+3$ weeks of gestation. $\mathrm{G}$ banding (Figure 1) and FISH (Figure 2) revealed a small (type I) CES SMC present in all cells. No additional data were available.

Case 36: This had an unusual (type III) CES chromosome as reported previously (patient 7). ${ }^{11}$ The SMC (Figure 1) was present in $19 \%$ of the cells of an AC performed at $14+6$ weeks of gestation and in 3\% of cells after FBS. It revealed a trisomy of 22p11-q13. Here, we report results of UPD studies, which indicated uniparental maternal heterodisomy 22 (UPHetD22mat) (Table 4). The amount of DNA from the SMC was below the detection limit of the assay. Although the paternal origin of the SMC was not proven, it is most likely of paternal origin. The boy was not dysmorphic at birth and reportedly showed normal development at age 6 months.

Case 40: This was previously reported (patient 6). ${ }^{11}$ An AC was performed at $14+5$ weeks of gestation. $G$ banding
(Figure 1) and FISH (Figure 2) showed a large (type II) CES SMC present in all cells. The woman considered termination of the pregnancy. No additional data were available.

\section{Familial SMCs}

Familial SMCs were found in 13 pregnancies (13 out of 42 , $30.9 \%$ ) from 11 unrelated women (Table 2). Seven (63.6\%) were inherited paternally and four (36.3\%) maternally. The familial SMCs were present in all cells. One pregnancy (case 2) showed two different cell lines containing one and two copies of the SMC, respectively. Three cases (Table 2) were studied for UPD, all with normal results.

Chromosome 13 or 21 Case 27: A very small bisatellited, metacentric SMC was found after an AC performed at $14+1$ weeks of gestation. FISH indicated a $13 p$ or $21 p$ isochromosome or translocation. The mother displayed the same SMC. The boy had no apparent anomalies at age 1 year.

Case 37: Following an AC performed at 16 weeks of gestation, a bisatellited SMC was seen in the amniocytes and in paternal blood lymphocytes. FISH indicated an origin from chromosome $13 p$ and/or $21 p$. At 28 weeks of gestation, the woman had a premature ablation of the placenta and an emergency Caesarean section. Birth weight was $770 \mathrm{~g}$, length $35 \mathrm{~cm}$, and Apgar 7/7/9 after $1 / 5 / 10 \mathrm{~min}$. At age 12 months, the boy was not dysmorphic and showed no signs of developmental delay.

Chromosomes 13 or 21 and chromosome 15 Case 6: This phenotypically normal woman had a female cousin with mental retardation of unknown origin. An AC was performed at $16+5$ weeks of gestation. A small bisatellited SMC was identified and also found in maternal lymphocytes. Using FISH, a small dicentric SMC with alphoid DNA of chromosomes 13 or 21 and of chromosome 15 was detected. This girl had no apparent anomalies at age 5 years

Chromosome 15 Case 17A: A small bisatellited SMC was identified after an AC performed at $15+5$ weeks of gestation and in maternal lymphocytes. FISH demonstrated a dicentric SMC(15) without the PW/ACR. Molecular studies indicated a normal biparental inheritance at loci D13S232, D13S218, D13S317, D13S796, D13S285, D14S597, D14S306, D14S617, D15S122, D15-ACTC,

Table 4 Short sequence repeat polymorphisms analyzed in case no. 36

\begin{tabular}{lccc}
\hline Locus & Alleles & Result \\
\hline D22S941 & Location & Mother - Father - Amniocytes & No paternal allele \\
D22S944 & $22 q 11.21$ & $235 / 243-245 / 247-235 / 243$ & Possibly Mendelian \\
D22S274 & $22 q 11.21$ & $162 / 164-164 / 162-162 / 164$ & Possibly Mendelian \\
D22S1169 & $22 q 13.31$ & $200 / 200-200 / 198-200 / 200$ & No paternal allele \\
\hline
\end{tabular}


D15S175, and D15S642, excluding UPD for chromosomes 13,14 , and 15. Fetal ultrasound was normal. The boy had no apparent anomalies at age 3 years.

Case 17B: At the age of 38, this woman had another AC showing the SMC. Molecular studies indicated biparental inheritance at loci D14S597, D14S306, D15S122, D15ACTC, and D15S642, excluding UPD14 and UPD15. Clinical findings at age 6 months were normal.

Case 39: After 2 years of sterility, a small dicentric SMC was identified in lymphocytes of the partner of a 28-yearold woman, and in lymphocytes of his father. Intracytoplasmatic sperm injection (ICSI) was performed without success. Thereafter, a pregnancy occurred spontaneously. Following CVS at $11+6$ weeks of gestation and FISH, an inverted duplication of chromosome 15 lacking the PW/ACR was identified. Molecular studies showed a normal biparental inheritance at different polymorphic markers (D15S1365, D15S817, D15S195, D15S523, and D15S533) excluding UPD15. The pregnancy commenced normally, but was not available for follow-up.

Chromosome 22 Case 2: An AC was performed at $14+1$ weeks of gestation. Two copies of a small metacentric, bisatellited SMC were present in $57 \%$ of the cells and one copy of the SMC in $43 \%$. The SMC was maternally inherited. FISH demonstrated a minute dicentric chromosome 22 made up of two short arms and two pericentromeric regions, but without the CECR. The girl was normal at an age 6 years.

Case 7A: In a 31-year-old woman, an AC was performed at $19+2$ weeks of gestation following a fetal ultrasound showing anhydramnios, spina bifida aperta, and cysticdysplastic kidneys. A small metacentric, bisatellited SMC was identified in amniocytes and in paternal lymphocytes. FISH indicated an isochromosome $22 \mathrm{p}$ with a partially duplicated centromere. The pregnancy was terminated.

Case 7B: Another AC in her next pregnancy showed the same SMC and an additional de novo translocation of chromosomes 4 and 5 . This boy had no apparent anomalies at age 4.5 years.

Case 18: This small metacentric bisatellited SMC was detected following an AC at 14 weeks of gestation. The SMC was found to be of paternal origin. FISH indicated an isochromosome 22p. The boy had no apparent anomalies at age 2.5 years.

Case 20: An AC was performed at $17+3$ weeks of gestation. A bisatellited metacentric SMC was found in the amniocytes and in paternal lymphocytes. Using FISH, the SMC was an isochromosome 22p. The boy had no apparent anomalies at age 2.5 years.

Case 26: This was previously reported (patient 9). ${ }^{11}$ In a twin pregnancy, an AC was performed at 15 weeks of gestation. An SMC was detected and using FISH, a der(22)t $(11 ; 22)$ extrachromosome was identified. A constitutional $11 ; 22$ translocation was identified in the cotwin and in the father. The affected twin had severe malformations and died on day one of life. ${ }^{11}$ The cotwin had no anomalies.

Case 28: Following an abnormal $(2.9 \mathrm{~mm})$ nuchal translucency, a 28-year-old woman had a CVS performed at 12 weeks of gestation. A small, bisatellited SMC was evident in all cells and in paternal lymphocytes. FISH indicated an isochromosome 22p. The girl was born at term. Weight was $3910 \mathrm{~g}$, length $53 \mathrm{~cm}$, and Apgar 8/10. Apart from adducted feet she had no apparent anomalies at the age of 4 months.

\section{Discussion}

So far, this is the largest FISH study of prenatally diagnosed SMCs. Apart from the detailed review of Crolla, ${ }^{10}$ so far only one large-scale study of the euchromatic DNA content in pre- and postnatal SMCs has been reported. ${ }^{7}$

\section{Frequencies of the different SMCs}

Our study shows a prevalence of $1 / 1032(n=42)$ for SMCs at prenatal diagnosis, $1 / 1492$ for de novo SMCs $(n=29)$, and $1 / 3328$ for the familial SMCs $(n=13)$. Previous studies reported SMC frequencies of $0.4 / 1000,{ }^{3} 0.8 / 1000,{ }^{21}$ $1 / 1000,^{5}$ and $1.5 / 1000 .^{2}$ The higher frequencies could possibly be explained by (i) nonrandom ascertainment of cases, (ii) withdrawal of materials at an earlier point of time in gestation, and/or (iii) greater maternal age. In our study, none of these possibilities is persuasive. The maternal age distribution was inconspicious, materials were withdrawn at usual points in time of gestation, and all but six pregnancies (14\%; Tables 1 and 2) were ascertained due to maternal age and/or anxiety. Therefore, we consider the frequency of $1 / 1000$ for prenatally diagnosed SMCs to be representative.

Table 3 classifies the SMCs in the present study. At a prevalence of 1/1602, heterochromatic SMCs (classes I and III; $n=27$ ) were almost twice as frequent as euchromatic SMCs (classes II, IV, and V; $n=15$ ) with a prevalence of 1/2884. Euchromatic SMCs usually originated de novo and accounted for approximately one half of de novo SMCs (48.2\%; 14 of 29); the remaining de novo SMCs were heterochromatic. Apart from one case, all familial SMCs were heterochromatic and, therefore, without phenotypic effects. In the one case (no. 26) with abnormalities, the SMC arose from a 3:1 malsegregation of a balanced translocation.

Regarding the morphology, we have shown that $57.1 \%$ of the prenatally diagnosed SMCs are bisatellited $(n=24)$. Five bisatellited SMCs $(5 / 24,20.8 \%)$ contained detectable euchromatin (class II; PW/ACR or CECR). About $32 \%$ of the SMCs were ring-like minutes $(n=13)$, and of these, $38 \%$ showed euchromatin (class IV minutes; $n=5$ ). Another $12 \%$ of the SMCs were miscellaneous (class V; $n=5$ ). These all occurred de novo and showed tentatively recognizable 
banding patterns: an acrocentric (class V) SMC proved to be a der(22)t $(11 ; 22)$ chromosome, a submetacentric SMC (case 10) was identified as an inverted duplication of chromosome $15 \mathrm{q} 24$ as reported previously, ${ }^{9}$ and three metacentric SMCs represented isochromosomes 12p and $18 \mathrm{p}$, respectively.

\section{FISH strategy}

Six different DNA probes (for $\beta$-satellite DNA on the acrocentric short arms; the alphoid DNA subsets on chromosomes 13/21, 14/22, and 15; the PWS/AS chromosomal region, and the CECR) are sufficient for a basic classification of bisatellited SMCs (classes I and II). However, as shown here and elsewhere, a subset of cases may require additional probes. ${ }^{7,11,17}$ The stepwise investigation of minute SMCs (classes III and IV) included (i) the identification of the $\alpha$-satellite suprachromosomal family by low-stringency hybridization allowing cross-hybridization between members of the same suprafamily, ${ }^{13}$ (ii) the identification of the chromosomal origin by highstringency (chromosome-specific) hybridization of alphoid DNA probes, and (iii) analysis of the euchromatin DNA content using region-specific probes such as BACs. ${ }^{7,11}$ There have been attempts to detect the euchromatin on SMCs by using of whole chromosome painting, ${ }^{16}$ but due to the presence of centromeric DNA in some paints, this approach is artifact prone: heterochromatic and euchromatic SMCs (classes I vs II or classes III vs IV) may be confused. This study has shown that the stepwise procedure is effective and fast; final results were obtained (usually within 1 week) for $92.3 \%$ (12 of 13) of the minute SMCs. All other (class V) SMCs were tentatively identified by their cytogenetic properties and required only confirmatory FISH studies. Overall, only one case (2.5\%; case 13) required the use of more complex FISH techniques. ${ }^{9}$

\section{Small (class I) bisatellited SMCs}

SMCs of the acrocentric short arms and small dicentric chromosomes 15 or 22 are assumed to be devoid of dosagesensitive genes. Nevertheless, it is widely assumed that they confer a small risk for congenital anomalies above the baseline risk of the general population. Interestingly, this study includes a case possibly supporting such extra risk. One (6\%) of the 17 pregnancies with a class I SMC featured bifid spine, dysplastic kidneys, anhydramnios, and a familial isochromosome 22p (case 7A). The clinical findings are not imputable to the presence of undetected euchromatin between the centromere and the CECR (chromosome 22q11.21) on this SMC, because they have not been previously reported with tri- or tetrasomy of chromosome 22q11. ${ }^{22}$ Neither can they be explained by imprinting defects caused by the possible presence of UPD22, because chromosome 22 is not known to harbor imprinted genes. ${ }^{23,24}$ The reduction to homozygosity of recessive mutations by UPD remains a remote possibility, because in rare cases, neural tube defects (NTDs) were associated with 22 q11 deletions. ${ }^{25,26}$ Oligohydramnios and absent/malformed kidneys have been reported with full trisomy $22 .{ }^{27}$ Our patient had no additional signs of trisomy 22 , or of a $22 \mathrm{q} 11$ deletion. In fact, the combination of kidney cysts and NTD appears to be extremely rarely associated with chromosomal aberrations: thus far, there has been only one report involving chromosome $3 .^{28}$ However, the combination has been reported with the VACTERL association, ${ }^{29}$ a relatively frequent disorder (1 in 5000 newborns) that has been linked with maternal diabetes, inhibition of cholesterol biosynthesis, and the Hedgehog signaling pathway. ${ }^{30}$ Therefore, we consider the abnormalities and the SMC(22) in case 7A to be most likely a chance association. Nevertheless, the data support that pregnancies with a class I SMC have a slightly increased risk for abnormalities.

\section{Prevalence of the CECR and possible maternal age effect}

The CECR was present in six SMCs (prevalence 1/7212) or, excluding the familial case 26 , in five de novo SMCs (1/8655). The de novo cases included a small ring chromosome (case 9), an atypical CES chromosome (case 36), ${ }^{11}$ and three typical CES chromosomes (cases 22, 33, and 40). ${ }^{17}$ There has been no previous report on the prevalence of SMCs conferring extra copies of the CECR at prenatal diagnosis. For the CES, a frequency between 1:50000 and 1:150000 was estimated from patients observed in Switzerland (OMIM 115470). The large difference between the pre- and postnatal data (1:8655 vs 1:50000-150000) requires explanation. Population-based investigations are likely to ascertain fewer cases of CES than prenatal studies for various reasons including spontaneous abortions, oligoor asymptomatic outcome in some patients, ${ }^{6,31}$ (also this study) and terminations of pregnancy. AMA could possibly be another factor. Hook and Cross $^{21}$ reported a significant maternal age effect for de novo SMCs in their study of 75000 prenatal diagnoses. Recently, Crolla et $a^{8}$ confirmed the maternal age effect for de novo SMCs(15), but for SMCs(22) their data were inconclusive. Considering that the inverted duplications of chromosomes 15 and 22 share similar origins because they both may arise in female meiosis from errors of recombination at sites of low copy repeats (LCRs), ${ }^{32-36}$ the higher frequency of CES chromosomes in this study $v s$ in the population could also, in part, be indicative of a maternal age effect.

\section{Minute ring-like SMCs (classes III and IV)}

Minute ring-like SMCs (classes III and IV) were identified in 13 pregnancies (3.0 per 10000 prenatal samples). All had occurred de novo. There were eight cases (61.5\%) of heterochromatic (class III) SMCs and of these, five resulted in children without anomalies carrying SMCs 6, 8, 11, 17, and 21 , respectively (cases 38, 3, 29, 30, and 25). Three 
pregnancies were terminated due to maternal anxiety. Five pregnancies (38.5\%) showed (class IV) SMCs conferring small proximal trisomies, but four of these were previously reported (case 13), terminated (cases 9 and 32), or not available for follow-up (case 34), and hence provided no new phenotypic information. A pregnancy with a mosaic SMC(19) (63\% at AC, 30\% at FBS; case 15) was informative regarding the phenotype. The child had no anomalies at age 3 years. There have been six previous cases with mosaic SMC(19) and a known outcome. Of these, two showed anomalies. ${ }^{10}$ Hence, including our case, mosaic de novo (class IV) SMCs(19) at prenatal diagnosis confer an empirical risk of approximately $20 \%$ for congenital anomalies.

\section{Uniparental disomy}

This study includes a case (no. 36) of maternal heterodisomy for chromosome 22 associated with a bisatellited SMC(22). Recently, the early postzygotic reduction of a chromosome to a SMC was identified as a mechanism to rescue a trisomic conceptus. ${ }^{24}$ Case 36 is the second example of trisomy rescue by fortuitous formation of an SMC from the paternal homolog $22 .{ }^{24}$ The SMC conferred trisomy for chromosome $22 \mathrm{p} 11-\mathrm{q} 13$, but was present in only $19 \%$ of amniocytes and $3 \%$ of lymphocytes. Hence, we consider the normal phenotype of the patient at age 6 months to be most likely due to the low degree of mosaicism for the SMC. Moreover, the case adds evidence to that maternal UPD 22 usually has no adverse effects. ${ }^{23,24}$

\section{Acknowledgements}

We thank Arleta Frensel for providing technical assistance, Prof Georg Klaus Hinkel for continuous support, and Dr Thomas Liehr for results (cases 32 and 38) using multifluor FISH and partial chromosome paints.

\section{Electronic-database information}

URLS and accession numbers for data in this article are as follows: Online Mendelian Inheritance in Man (OMIM, http://www.ncbi.nlm. nih.gov/Omim) for the CES (MIM 115470) and isochromosome 12p (OMIM 601803).

\section{References}

1 Ferguson-Smith MA, Yates JR: Maternal age specific rates for chromosome aberrations and factors influencing them: report of a collaborative European study on 52965 amniocenteses. Prenat Diagn 1984; 4 (Spec No): 5-44.

2 Sachs ES, Van Hemel JO, Den Hollander JC, Jahoda MG: Marker chromosomes in a series of 10000 prenatal diagnoses. Cytogenetic and follow-up studies. Prenat Diagn 1987; 7: 81-89.

3 Warburton D: De novo balanced chromosome rearrangements and extra marker chromosomes identified at prenatal diagnosis: clinical significance and distribution of breakpoints. Am J Hum Genet 1991; 49: 995-1013.

4 Blennow E, Bui TH, Kristoffersson U et al: Swedish survey on extra structurally abnormal chromosomes in 39105 consecutive prenatal diagnoses: prevalence and characterization by fluorescence in situ hybridization. Prenat Diagn 1994; 11: 1019-1028.
5 Brondum-Nielsen K, Mikkelsen M: A 10-year survey, 1980-1990, of prenatally diagnosed small supernumerary marker chromosomes, identified by FISH analysis. Outcome and follow-up of 14 cases diagnosed in a series of 12699 prenatal samples. Prenat Diagn 1995; 15: 615-619.

6 Hastings RJ, Nisbet DL, Waters K, Spencer T, Chitty LS: Prenatal detection of extra structurally abnormal chromosomes (ESACs): new cases and a review of the literature. Prenat Diagn 1999; 19: 436-445.

7 Starke H, Nietzel A, Weise A et al: Small supernumerary marker chromosomes (SMCs): genotype-phenotype correlation and classification. Hum Genet 2003; 114: 51-67.

8 Crolla JA, Youings SA, Ennis S, Jacobs PA: Supernumerary marker chromosomes in man: parental origin, mosaicism and maternal age revisited. Eur J Hum Genet 2005; 13: 154-160.

9 Spiegel M, Hickmann G, Senger G, Kozlowski P, Bartsch O: Two new cases of analphoid marker chromosomes. Am J Med Genet 2003; 116A: 284-289.

10 Crolla JA: FISH and molecular study of autosomal supernumerary marker chromosomes excluding those derived from chromosome 15: II. Review of the literature. Am J Med Genet 1998; 75: 367-381.

11 Bartsch O, Rasi S, Hoffmann K, Blin N: FISH of supernumerary marker chromosomes (SMCs) identifies six diagnostically relevant intervals on chromosome $22 \mathrm{q}$ and a novel type of bisatellited SMC(22). Eur J Hum Genet 2005; 13: 592-598.

12 Plattner R, Heerema NA, Yurov YB, Palmer CG: Efficient identification of marker chromosomes in 27 patients by stepwise hybridization with alpha-satellite DNA probes. Hum Genet 1993; 91: $131-140$.

13 Alexandrov IA, Medvedev LI, Mashkova TD, Kisselev LL, Romanova LY, Yurov YB: Definition of a new alpha satellite suprachromosomal family characterized by monomeric organization. Nucleic Acids Res 1993; 21: 2209-2215.

14 Bartsch O, Wagner A, Hinkel GK et al: FISH studies in 45 patients with Rubinstein-Taybi syndrome: deletions associated with polysplenia, hypoplastic left heart and death in infancy. Eur $J$ Hum Genet 1999; 7: 748-756.

15 Zhu G, Bartsch O, Skrypnyk C et al: Failure to detect DUP25 in lymphoblastoid cells derived from patients with panic disorder and control individuals representing European and American populations. Eur J Hum Genet 2004; 12: 505-508.

16 Liehr T, Pfeiffer RA, Trautmann U: Typical and partial cat eye syndrome: identification of the marker chromosome by FISH. Clin Genet 1992; 42: 91-96.

17 McTaggart KE, Budarf ML, Driscoll DA, Emanuel BS, Ferreira P, McDermid HE: Cat eye syndrome chromosome breakpoint clustering: identification of two intervals also associated with 22q11 deletion syndrome breakpoints. Cytogenet Cell Genet 1998; 81: $222-228$.

18 Cheng SD, Spinner NB, Zackai EH, Knoll JH: Cytogenetic and molecular characterization of inverted duplicated chromosomes 15 from 11 patients. Am J Hum Genet 1994; 55: 753-759.

19 James RS, Temple IK, Dennis NR, Crolla JA: A search for uniparental disomy in carriers of supernumerary marker chromosomes. Eur J Hum Genet 1995; 3: 21-26.

20 Hengstschläger $\mathrm{M}$, Bettelheim $\mathrm{D}$, Drahonsky R, Deutinger J, Bernaschek G: Prenatal diagnosis of a de novo supernumerary marker derived from chromosome 16. Prenat Diagn 2001; 21: $477-480$.

21 Hook EB, Cross PK: Extra structurally abnormal chromosomes (ESAC) detected at amniocentesis: frequency in approximately 75000 prenatal cytogenetic diagnoses and associations with maternal and paternal age. Am J Hum Genet 1987; 40: 83-101.

22 Rosias PPR, Sijstermans JMJ, Theunissen PMVM et al: Phenotypic variability of the cat eye syndrome. Case report and review of the literature. Genet Couns 2001; 12: 273-282.

23 Schinzel AA, Basaran S, Bernasconi F, Karaman B, Yuksel-Apak M, Robinson WP: Maternal uniparental disomy 22 has no impact on the phenotype. Am J Hum Genet 1994; 54: 21-24. 
24 Bartels I, Schlueter G, Liehr T: Supernumerary small marker chromosome (SMC) and uniparental disomy 22 in a child with confined placental mosaicism of trisomy 22: trisomy rescue due to marker chromosome formation. Cytogenet Genome Res 2003; 101: $103-105$.

25 Nickel RE, Magenis RE: Neural tube defects and deletions of 22q11. Am J Med Genet 1996; 66: 25-27.

26 Forrester S, Kovach MJ, Smith RE, Rimer L, Wesson M, Kimonis VE: Kousseff syndrome caused by deletion of chromosome 22q11-13. Am J Med Genet 2002; 112: 338-342.

27 Tinkle BT, Walker ME, Blough-Pfau RI, Saal HM, Hopkin RJ: Unexpected survival in a case of prenatally diagnosed nonmosaic trisomy 22: clinical report and review of the natural history. Am I Med Genet 2003; 118A: 90-95.

28 Allderdice PW, Browne N, Murphy DP: Chromosome 3 duplication q21-qter deletion p25-pter syndrome in children of carriers of a pericentric inversion inv(3)(p25q21). Am J Hum Genet 1975; 27: 699-718.

29 Krapp M, Geipel A, Germer U, Krokowski M, Gembruch U: Firsttrimester sonographic diagnosis of distal urethral atresia with megalourethra in VACTERL association. Prenat Diagn 2002; 22: 422-424.

30 Bale AE: Hedgehog signaling and human disease. Annu Rev Genomics Hum Genet 2002; 3: 47-65.
31 Bartsch O, Aksu F, Fenner A, Schwinger E: [Atypical cat eye syndrome. Fluorescence in situ hybridization of metaphase chromosomes]. Monatsschr Kinderheilkd 1992; 140: 460-463.

32 Mignon C, Malzac P, Moncla A: Clinical heterogeneity in 16 patients with inv dup 15 chromosome: cytogenetic and molecular studies, search for an imprinting effect. Eur J Hum Genet 1996; 4: 88-100.

33 Crolla JA, Howard P, Mitchell C, Long FL, Dennis NR: A molecular and FISH approach to determining karyotype and phenotype correlations in six patients with supernumerary marker(22) chromosomes. Am J Med Genet 1997; 72: 440-447.

34 Christian SL, Fantes JA, Mewborn SK, Huang B, Ledbetter DH: Large genomic duplicons map to sites of instability in the PraderWilli/Angelman syndrome chromosome region (15q11-q13). Hum Mol Genet 1999; 8: 1025-1037.

35 Edelmann L, Pandita RK, Spiteri E et al: A common molecular basis for rearrangement disorders on chromosome 22q11. Hum Mol Genet 1999; 8: 1157-1167.

36 Roberts SE, Maggouta F, Thomas NS, Jacobs PA, Crolla JA: Molecular and fluorescence in situ hybridization characterization of the breakpoints in 46 large supernumerary marker 15 chromosomes reveals an unexpected level of complexity. Am J Hum Genet 2003; 73: 1061-1072. 